\title{
Festividade de São Sebastião, de Cachoeira do Arari: uma possibilidade para o desenvolvimento do turismo cultural na Ilha do Marajó, Brasil
}

\section{Feast of San Sebastian, in Cachoeira do Arari: a chance for the development of cultural tourism in Marajó island, Brazil}

\section{Fiesta de San Sebastián, en Cachoeira do Arari: una oportunidad para el desarrollo del turismo cultural en la isla de Marajó, Brasil}

Marinete Silva Boulhosa ${ }^{1}$

\begin{abstract}
Resumo: O presente artigo aborda a religiosidade do povo amazônico, que tem nas festas de santos católicos uma das maiores manifestações da identidade e da cultura amazônica. Trabalhando a partir da descrição, análise e interpretação da Festividade de São Sebastião de Cachoeira do Arari, na Ilha do Marajó, que se destaca como a maior manifestação em homenagem a esse santo no Brasil, a qual teve seu registro aprovado no ano de 2013 pelo Instituto do Patrimônio Histórico e Artístico Nacional, como patrimônio cultural do Brasil. O objetivo aqui é discutir sobre o aproveitamento turístico desta manifestação religiosa, por intermédio do turismo cultural, destacando sua importância na contribuição do resgate, valorização e promoção da cultura marajoara. A base teórica e metodológica está na antropologia social e cultural, tendo como método de investigação a etnografia, compreendendo-a como uma experiência de imersão total que possibilita aproximação maior com as práticas culturais da gente marajoara e maiores recursos de informações para a proposição do turismo cultural, como fator de alternativa para o desenvolvimento da região.
\end{abstract}

Palavras-chave: Religiosidade; turismo cultural; Ilha do Marajó; Festa de santo; Festividade de São Sebastião.

Abstract: This paper deals with the religiosity of the Amazonian people, which has in the catholic saints feasts one of the largest manifestations of identity and Amazonian culture. From the description, analysis and interpretation of the Festival of San Sebastian of Cachoeira do Arari, in Marajó Island, which stands as the largest demonstration in honor of this saint in Brazil, which had its registration approved in 2013 by the Institute Heritage National Historical and Artistic, such as cultural heritage of Brazil. The goal here is to discuss the tourist use of this religious manifestation, through cultural tourism, highlighting its importance in the rescue contribution, appreciation and promotion of marajoara culture. The theoretical and methodological base is in social and cultural anthropology, with the ethnography research method, understanding it as a total immersion experience that enables a closer relationship with the cultural practices of marajoara people and enables higher information resouces to propose cultural tourism as an alternative factor for the development of the region.

\footnotetext{
${ }^{1}$ Mestre em Antropologia (UFPA), Bacharel em Turismo (UFPA), Professora do Eixo de Turismo, Hospitalidade e Lazer do Instituto Federal do Pará (IFPA) - Campus Belém. E-mail: neteboulhosa@ gmail.com
} 
Keywords: Religiosity; cultural tourism; Marajó Island; holy feast; Feast of St. Sebastian.

Resumen: Este artículo trata de la religiosidad de los pueblos amazónicos, que tiene en los santos católicos una de las mayores manifestaciones de la identidad y la cultura amazónica. A partir de la descripción, el análisis y la interpretación del Festival de San Sebastián, la ciudad de Cachoeira do Arari, en la Isla de Marajó, que se erige como la mayor manifestación en honor a este santo en Brasil, que había aprobado su registro en 2013 por el Instituto patrimonio histórico y artístico Nacional, como el patrimonio cultural de Brasil. El objetivo aquí es discutir el uso turístico de esta manifestación religiosa, a través del turismo cultural, destacando su importancia en la contribución de rescate, reconocimiento y promoción de la cultura Marajoara. La base teórica y metodológica es en antropología social y cultural, con el método de investigación de la etnografía, entendiéndola como una experiencia de inmersión total que permite una relación más estrecha con las prácticas culturales de las personas marajoara y proporciona más recursos de información para proponer turismo cultural como un factor alternativa para el desarrollo de la región.

Palabras clave: Religiosidad; turismo cultural; Isla de Marajó; santa fiesta; Fiesta de San Sebastián.

\section{Introdução}

A religiosidade, com predomínio do catolicismo popular, sem perder de vista as outras concepções religiosas, é algo marcante na vida do homem amazônico, em que as festas de santos fazem parte da vida das cidades da região. Cada município possui seu calendário de festa em homenagem a um santo padroeiro e, essas celebrações, constituem-se sempre numa manifestação coletiva, onde a oração individual dá lugar à missa, à ladainha, à novena e à festa.

Assim, as festas de santo cumprem uma função essencial na vida do homem amazônico, nos quais os santos, ou melhor, suas imagens, assumem um caráter divino, como bem já trabalhado por Eduardo Galvão (1955), em "Santos e visagens: um estudo da vida religiosa de Itá", Isidoro Alves (1980) em "O carnaval devoto: um estudo sobre a festa de Nazaré em Belém” e Raymundo Heraldo Maués (1995 e 1999) em "Padres, pajés, santos e festas. Catolicismo popular e controle eclesiástico" e "Uma outra invenção da Amazônia: religiões, histórias, identidades".

De acordo com Maués (1999), a religiosidade é um dos elementos que compõem a identidade da sociedade amazônica e, quem primeiro estudou a questão da diversidade religiosa do homem amazônico, do ponto de vista antropológico, foi Eduardo Galvão na obra "Vida religiosa do caboclo da Amazônia", de 1953.

Porém, as festas religiosas que ocorrem na região, como é o caso do Círio em Belém, considerada a maior festa cristã do planeta, o círio da cidade de Vigia, mais antigo que o de Belém, a Festa do Sairé em Santarém, que remonta ao período colonial na Amazônia, a Marujada de Bragança, festa em homenagem a São Benedito e a Festividade de São Sebastião, em Cachoeira do Arari, maior festa em homenagem a este santo no Brasil, entre outras, são eventos de grande importância para essas cidades e para a região. Ultrapassam a dimensão religiosa, destacando-se como os mais importantes eventos turísticos dessas cidades, que reúnem milhares de pessoas de várias partes da Amazônia, do Brasil e de outros países. 
Assim, esses eventos religiosos, por sua natureza e dimensões que envolvem religião, economia, cultura, política/ideologia e sociedade, e pela capacidade de atração que exercem em um número cada vez maior de pessoas, passam a constituir-se em atrativos turísticos culturais das cidades onde ocorrem. O turismo cultural é o acesso ao patrimônio cultural, à história, às tradições, à religião, ao modo de vida de uma comunidade, onde o turista não busca apenas o lazer, mas também conhecer aspectos da história e da cultura dos povos visitados (MOLETTA, 2001).

O presente artigo foi elaborado a partir da pesquisa de mestrado em antropologia, realizada em 2007, na Universidade Federal do Pará, no Programa de Pós-Graduação em Ciências Sociais. Tem por objetivo apresentar, caracterizar e interpretar a Festividade de São Sebastião que ocorre em Cachoeira do Arari, Ilha do Marajó-PA, que teve seu registro aprovado em 2013 pelo Instituto do Patrimônio Histórico e Artístico Nacional (IPHAN), que a reconhece como patrimônio cultural do Brasil, e fazer uma reflexão sobre o aproveitamento turístico desta festividade.

Para o desenvolvimento da pesquisa, trabalhou-se com o referencial teórico que articula cultura, turismo e religiosidade. A abordagem teórica adotada foi da antropologia social ou cultural, que abrange aspectos da história, economia, costumes, conhecimentos, religião, identidades, entre outros. Tem como método de investigação a etnografia, da qual Laplantine (2003) salienta tratar-se de uma experiência de imersão total. É a forma de o antropólogo observar e interpretar uma sociedade na sua observação direta e no comunicar-se com ela. E foi nesta perspectiva que este trabalho se desenvolveu. Este método possibilitou analisar com maior clareza aspectos fundamentais da sociedade e cultura marajoara e compartilhar reflexões sobre o desenvolvimento do turismo cultural no Marajó.

\section{Turismo cultural e eventos religiosos}

O turismo cultural, entendido como a vinda de pessoas de fora da comunidade receptora motivadas completamente ou em parte por interesses na oferta histórica, artística, científica ou no estilo de vida, tradições da comunidade, religião, grupo ou instituição (PIRES, 2001), desencadeia uma série de bens e serviços nas comunidades receptoras, capaz de contribuir para o desenvolvimento socioeconômico das mesmas.

A Amazônia, aqui com destaque o Marajó, maior ilha entre rio e mar do planeta, tem em seus atrativos naturais um dos principais motivadores de viagens turísticas, em função da diversidade faunística e florística dessa região, entrecortada por rios e igarapés piscosos, vegetação heterogênea, com destaque para floresta tropical e os campos naturais pontilhados por fazendas de gado vacum e búfalos, algumas originadas no Brasil colônia. Essas características naturais, juntamente com a longa história de ocupação da ilha, cujos marcos podem ser observados na fundação das cidades, na introdução da pecuária, na constituição histórico-cultural dos habitantes da ilha, fazem do Marajó um espaço de grande apelo ambiental. Tanto é assim, que no ponto de vista do turismo, no processo de descentralização dessa atividade no Pará, em 2001, na elaboração do Plano de Desenvolvimento Turístico do Pará (PDT Pará), o Marajó constituiu-se em Polo de Desenvolvimento do Turismo do Estado. ${ }^{2}$

\footnotetext{
${ }^{2} \mathrm{O}$ conceito de polo turístico foi implantado no Brasil na década de 1990 pelo Ministério da Indústria, Comércio de Turismo quando da elaboração de programas para o desenvolvimento do turismo no país. Os polos são áreas consideradas prioritárias para investimentos e se constituem destinos turísticos consolidados, apresentando
} 
Nas pesquisas para a elaboração do Plano de Desenvolvimento Turístico (PDT Pará) (PARÁ, 2001), considerando, naturalmente, as características ambientais da ilha, a oferta de produtos e serviços existentes e a demanda turística real, os principais segmentos turísticos do Marajó identificados foram o ecoturismo e o turismo rural, os quais possuem expressiva demanda doméstica, regional e nacional. Todavia, as pesquisas também revelam que a ilha do Marajó possui potencial para outros segmentos, entre eles, o turismo cultural. No Relatório Executivo do Plano Estratégico de Turismo do Estado do Pará - 2012 - 2020 -, o Marajó, novamente confirma seu destaque, pois, no contexto da Amazônia, o Pará, em termos de posicionamento de produtos no mercado internacional, está em segundo lugar na região, precedido por Manaus, com dois produtos: Belém e Ilha do Marajó (PARÁ, [s.d.]).

Inúmeros eventos culturais possuem destaque na Ilha, como é o caso dos Festivais do Camarão de Afuá e Muaná, Festival do Açaí de São Sebastião da Boa Vista, Círio de Soure, Festividade de São Sebastião de Cachoeira do Arari, entre outros, que provocam grande movimentação de pessoas à Ilha.

Pelas características religiosas do povo amazônico, as quais serão tratadas a seguir, os eventos religiosos na região ganham sempre destaque no calendário festivo dos municípios e caracterizam-se como principais motivadores de viagem turistas. Esses eventos, que embora tenham um caráter religioso, sempre extrapolam as questões religiosas, configurando-se como importantes momentos de sociabilidade, de expressão de crenças, valores, tradições, identidades, padrões de comportamentos, particularizam e diferenciam, mas também universalizam o ser e o fazer desse povo amazônico.

Ângelo (2011) tratando do segmento do turismo cultural, salienta que a cultura material e imaterial delimita o fator de motivação de viagem e o que chama a atenção do turista é o que o difere do outro.

O desenvolvimento turístico de uma localidade que possui símbolos refletidos na sua cultura material ou imaterial parece delimitar o fator de motivação da demanda por meio de tais recursos. Dos recursos mais relevantes percebe-se uma identificação com tradições, crenças e valores de cada raça, etnia, ou qualquer fator de diferenciação, que corresponda à ideia de alteridade.

O que parece chamar a atenção dos turistas é o que o difere do outro. Pelas diferenças buscam-se as diversas identidades alocadas em crenças e valores, diferenciados por meio da cultura material e imaterial (ÂNGELO, 2011, p. 7).

Os eventos religiosos, no contexto amazônico, para além de suscitar a fé e a devoção, podem ser encarados como atrativos turísticos culturais capazes de contribuir para o fomento do turismo na região do Marajó, haja vista o que já ocorre em Belém, com o círio de Nossa Senhora de Nazaré, considerado o mais importante produto turístico do estado do Pará e que atrai mais de 70 mil turistas todos os anos para a capital, cujos efeitos dessa presença são percebidos em vários setores da economia, desencadeando outras atividades e novos arranjos produtivos.

\section{A Ilha do Marajó: realidades e potencialidades}

A Ilha do Marajó está situada ao norte do Brasil, entre o estado de Macapá, o oceano Atlântico, baía do Marajó e rio Pará. É a maior ilha flúvio-marinha do mundo, com uma área de

potencialidades para o desenvolvimento dos vários segmentos turísticos. No estado do Pará os polos turísticos são: Polos Belém, Amazônia Atlântica, Araguaia-Tocantins, Marajó, Tapajós e Xingu. 
49.606 $\mathrm{Km}^{2}$, formada por 12 municípios, com uma população de 482.285 habitantes (Instituto Brasileiro de Geografia e Estatística [IBGE], 2010), sendo a maior do arquipélago marajoara. O Marajó está dividido em duas regiões particulares: a leste, a região dos campos naturais e a oeste, a região da densa floresta tropical, que se estende até sudoeste da ilha.

A Ilha do Marajó possui destaque especial no Estado sob o ponto de vista econômico, natural e turístico. É um dos principais fornecedores de produtos extrativistas, frutíferos, pesqueiros, agrícolas e pecuários para a capital do estado. Do ponto de vista do turismo, o Marajó, desde a década de 1970, passou a receber incentivos do governo estadual para o desenvolvimento da atividade turística na ilha, que tem nas praias, campos naturais, zonas de florestas primárias e nas fazendas de gado e búfalo, como São Jerônimo, Bom Jesus, Sanjo e Carmo a oferta de atrativos naturais. Esses atrativos são complementados com a riqueza da cultura marajoara, manifestada por intermédio da sua gastronomia, danças, músicas, artesanatos, cerâmica, modo de vida e seus eventos festivos e religiosos, que possuem destaque especial no calendário de eventos das cidades do Marajó.

Porém, apesar dos vastos recursos turísticos, pesqueiro, extrativista, frutífero e de grãos a região sofre com choques paradoxais, pois, ao lado desses recursos naturais e culturas, o Marajó vive um drama social e econômico marcado pela pobreza, analfabetismo e exclusão social em seus mais diversos sentidos (BOULHOSA, 2001).

Dados oficiais do IBGE de 1998 indicaram que cerca de $90 \%$ da população é pobre, vivendo muitos, em situação de miséria absoluta. Essa realidade se manteve nos números do IBGE de 2010, quando revelou que, do total da população de 482.285 habitantes, 180.048 estão em situação de extrema pobreza (IBGE, 2010). Sobre uma das principais atividades econômicas da ilha, a pecuária, é possível afirmar que se encontra estagnada, pois é praticamente a mesma desde a colonização, sem apresentar grandes processos de modernização.

Atualmente, nos municípios de Cachoeira do Arari e Salvaterra vem se desenvolvendo a monocultura do arroz, porém, tal atividade, até o momento, tem gerado mais conflitos de terra nos campos do Marajó e problemas ambientais do que desenvolvimento para a região e, ainda, não se percebeu a contribuição efetiva desta atividade na melhoria da qualidade de vida da população local. Se não houver maior gerenciamento e intervenção do poder público, corre-se o risco de ver nessa atividade a reprodução do que ocorreu, desde o período colonial, com a pecuária extensiva na ilha, que levou o Marajó a ser o mais importante centro pastoril do estado àquela época, mas, para a população local, em termos de desenvolvimento, não significou quase nada. Pelo contrário, as situações de exploração, irregularidades trabalhistas e privação de direitos caracterizaram muitos empreendimentos pecuários no local.

Diante dos dados revelados pelo IBGE, o governo do estado iniciou várias ações no sentido de mudar a realidade socioambiental da grande ilha. Entre essas ações ocorreu a inclusão do turismo como atividade econômica que poderia contribuir para a melhoria da qualidade de vida da população local. Essa valorização do turismo refletia, na época, a mudança da base produtiva do estado que, naquele ano, em 1996, introduziu o turismo como importante elemento para promover o desenvolvimento sustentável regional.

\section{As festas de santos e o santo da festa: a religiosidade do homem amazônico}

Os aspectos religiosos da cultura amazônica apresentam uma grande riqueza de crenças, mitos, concepções e práticas que, somadas à diversidade religiosa indígena, tem-se uma riqueza 
ainda maior no que diz respeito à diversidade cultural das populações amazônicas (MAUÉS, 1999).

O catolicismo popular ${ }^{3}$ de várias áreas da Amazônia, já investigadas por inúmeros pesquisadores, centra-se na crença e no culto dos santos. Só os santos são objeto de culto e esse culto se expressa, frequentemente, por meio das festas (MAUÉS, 2011).

Sobre a religiosidade na Amazônia, Eduardo Galvão declara:

A religiosidade do caboclo se manifesta, sobretudo, no culto dos santos, ou mais propriamente no de suas imagens locais, a que se empresta caráter de divindade com poderes de ação imediata e não apenas representações de intermediários entre uma força superior e o homem. A expressão máxima do culto dos santos se observa na festividade com que se celebra o "dia do santo". Cada povoado, sítio, ou comunidade tem o seu santo padroeiro, e alguns mais, de devoção (GALVÃO, 1953, p. 2).

A religiosidade do amazônida, de acordo com Galvão (1953), está ainda entre duas ordens de divindade: aquela que define a sua relação com os seres sobrenaturais que habitam as florestas, rios e igarapés, ou seja, os bichos visagentos, os encantados ${ }^{4}$, companheiros do fundo, e aquela crença nos santos, no poder das orações, promessas e festas. A crença nos seres encantados, embora não faça parte do corpo das crenças católicas, como orienta o autor, são observadas pelos grupos, portanto, fazem parte de sua religião, pois exprimem relações com o sobrenatural.

Alves (1980) afirma que, quando uma sociedade ou um de seus segmentos sai do ordinário de sua rotina para viver anualmente o extraordinário de eventos ritualizados é porque tal acontecimento tem a ver com a própria existência do corpo social. Baseado em Geertz (1989), o autor então indica que essas manifestações simbólicas são inscritos que podem ser lidos e interpretados. Maués (1995) ao tratar das festas de santo e fazer referência a Marcel Mauss e o conceito de fato social total, acrescenta:

Festas religiosas populares constituem, ademais, por sua própria natureza ritualística, momentos extraordinários na vida das populações ou comunidades que as realizam, possuindo aquele caráter de fato social total de que nos fala Marcel Mauss, onde se exprimem, "ao mesmo tempo e de uma só vez", uma grande quantidade de fenômenos, não só de natureza religiosa, mas também fenômenos jurídicos, morais, políticos, econômicos, estéticos etc. Na mesma linha de pensamento deste autor, essas festas constituem formas de prestações totais, uma espécie de potlatch, onde a obrigação de dar, receber e retribuir se estabelece não

\footnotetext{
3 A expressão "Catolicismo popular" aqui empregada faz referência ao utilizado por Maués (1999) para fazer distinção daquele catolicismo "oficial”, professado pela igreja. Esse catolicismo, esclarece o autor, não tem travas ou restrições e, por isso, permite o comportamento de brincadeira e irreverências das pessoas que festejam os santos. ${ }^{4}$ Maués (1995; 1999) esclarece que a crença no Encantado se refere a seres que são normalmente invisíveis às pessoas comuns, e que habitam "no fundo", numa região abaixo da superfície terrestre, subterrânea ou subaquática, que se manifestam de forma distinta. Quando se manifestam nos rios e igarapés, sob forma de cobras, peixes, botos etc. são chamados de Bichos do fundo, considerados perigosos. Quando se manifestam sob forma humana, são chamados de oiaras; aparecem como se fossem pessoas conhecidas e desejam levar para o fundo. A terceira forma de manifestação é aquela em que eles permanecem invisíveis, incorporando-se nos pajés, figura central do ritual da pajelança; quando isso ocorre, eles são chamados de caruanas ou guias.
} 
somente entre os indivíduos humanos, mas também na relação entre os homens e os santos, os homens e a divindade (MAUÉS 1995, p.316).

Dentro da ideia do dar e receber, é que Maués (1999) trabalha as bases do catolicismo popular, o qual define "como conjunto de crenças e práticas socialmente reconhecidas como católicas, de que participam, sobretudo, os não-especialistas do sagrado, quer pertençam às classes subalternas ou às classes dominantes". O autor afirma que sem o milagre do santo, que é a graça concedida em troca da prece ou da promessa, não haveria tal catolicismo. A promessa, também informa Galvão (1953), é o ponto focal das relações entre os homens e os santos, enquanto o milagre é a expressão máxima da ação do santo. E é exatamente o milagre, que dá origem à festa, ou seja, à informalidade, à alegria, à brincadeira, à aproximação, que acaba por figurar como o lado profano das homenagens aos santos. Mas a festa é, dentro do conceito do catolicismo popular, a ocasião em que os fiéis homenageiam o santo e pagam suas promessas.

$\mathrm{Na}$ verdade, é possível afirmar que, no Brasil, as festas estão intimamente relacionadas à religião. Da Matta (1974, apud ALVES, 1980) ao estudar as festas brasileiras, identifica que as mesmas estruturas simbólicas que aparecem numa festa como o carnaval, aparecem também nas festas de santo.

Alves (1980) em seu trabalho sobre a festa de Nazaré em Belém do Pará, constata "que a um só tempo estão operando a devoção, a ordem consagrada, própria do rito sacral, e a informalidade, a descontração, a alegria da festa". O sagrado e o profano, assim, longe de serem opostos absolutos, constituem-se categorias que operam simultaneamente. A festa, esse carnaval devoto, no dizer de Alves (1980) é, a um só tempo, um conjunto de atos litúrgicos que celebram um santo padroeiro e também de atos de encontro, de solidariedade, de neutralização de diferenças.

Este carnaval devoto de que fala Isidoro Alves (1980), sem ignorar certamente os conflitos internos existentes, não se define como movimento de total oposição. Na verdade, funciona como agente de equilíbrio dos fatos e agentes em ação; esta carnavalização é assim, também, uma forma de devoção.

Assim, por constituir-se uma das mais significativas formas de expressão do homem nativo da Amazônia, as festas de santo, não obstante o controle eclesiástico que tenta disciplinar as manifestações populares que se apresentam sempre de forma efervescente, lúdica, carnavalesca, ou mesmo profana, sob o olhar de quem tentar controlar, expressam, na verdade, a identidade desse amazônida.

Raymundo Maués (1999) tomando como exemplo a maior festa de santo, que é o Círio de Nazaré de Belém do Pará, afirma que a festa de santo é um dos elementos fundamentais da identidade nativa regional.

Vale lembrar, no entanto, que todos os esforços controladores da hierarquia eclesiástica, tentando disciplinar esse evento, têm encontrado limites numa forma de resistência que é bem própria da cultura do povo, que expressa também sua identidade amazônica através do culto de Nossa Senhora de Nazaré, até mesmo exportando esse culto para outras regiões, haja vista a realização do Círio de Nazaré em Brasília, no Rio de Janeiro e em várias outras capitais brasileiras (MAUÉS, 1999, p. 95). 


\section{A Festividade de São Sebastião em Cachoeira do Arari}

Cidade localizada na região de campos naturais do Marajó, às margens do rio Arari, criada a partir da expansão da colonização portuguesa na ilha, Cachoeira do Arari, tem na festividade de São Sebastião o seu mais importante evento festivo.

Recebendo influências externas desde o período colonial pelas missões religiosas, o Marajó tem nas festas de santos, uma das mais importantes manifestações culturais e os principais eventos dos municípios. Ao longo do ano, inúmeras homenagens aos santos da igreja católica são realizadas, eventos esses que são antecedidos com peregrinações, esmolações, ladainhas, encontros e rezas nas sedes das cidades, fazendas e vilas, além de outros eventos relacionados, como corridas de cavalos, leilões, bingos, festas dançantes, etc.

Esses eventos costumam movimentar um número muito grande de pessoas, que se deslocam para as sedes dos municípios para acompanhar a imagem do santo, pagar promessas, fazer pedidos, participar do lado lúdico do evento e, também, comercializar produtos diversos, pois essas festas são ótimas oportunidades para as vendas, pela quantidade de pessoas que atraem.

Dentre as festas de santos realizadas no Marajó, a festividade de São Sebastião em Cachoeira do Arari destaca-se no calendário festivo da Ilha como uma das maiores manifestações em homenagem a este santo. Segundo informações não oficiais da Secretaria Municipal de Turismo de Cachoeira do Arari, mais de 10 mil pessoas chegam à cidade para participar da festa. Por sua importância, a festividade teve seu registro aprovado em 2013 pelo Instituto do Patrimônio Histórico e Artístico Nacional (IPHAN), compondo atualmente o patrimônio cultural do Brasil.

A festividade inicia-se em julho, com a peregrinação da imagem do santo e tem seu encerramento em 20 de janeiro, dia de São Sebastião. Entre o início das peregrinações e o encerramento da festividade, inúmeros eventos ocorrem, atraindo pessoas de várias regiões do Brasil e do estado.

Considerado padroeiro dos vaqueiros e fazendeiros no Marajó, São Sebastião, chamado também pela população local de Glorioso São Sebastião, é o santo que protege os animais contra as doenças, a seca, a fome e as inundações, sendo assim venerado e respeitado por um grande número de pessoas.

\section{Os momentos e os símbolos da festividade de São Sebastião}

A festividade de São Sebastião tem duração de quase sete meses, pois sua preparação se inicia em julho com a peregrinação da imagem do santo, a qual sai da igreja de Nossa Senhora da Conceição, localizada na sede de Cachoeira do Arari, e é levada a algumas localidades do município e às fazendas, percorrendo inclusive outros municípios da Ilha, como Santa Cruz do Arari, Ponta de Pedras, Chaves e Muaná, angariando donativos para a festa. Na peregrinação, são arrecadadas doações em dinheiro e animais, como gado, porcos, cavalos, galos, entre outros, os quais são leiloados durante a festividade.

A imagem peregrina é levada em comitiva de rezadores chamada de Comissão de Foliões, um grupo formado por quatro homens: o mestre-sala, o violeiro, o bandeireiro e o tamboreiro. Eles são responsáveis pela guarda do santo, pelas cerimônias que acontecem nas fazendas, e pelas anotações das Ordens, ou seja, as doações feitas pelos fazendeiros e devotos. Essas Ordens e 
donativos ao santo têm grande importância para os devotos de São Sebastião, porque representam a proteção do gado e das criações, garantindo um verão sem muitas perdas.

Esses foliões passam meses longe de seus lares e familiares, peregrinando com a imagem do santo, enfrentando as mais diversas experiências pelos campos do Marajó, ora andando a pé, ora montados a cavalo, ora sob o sol escaldante, ora sob chuva torrencial. "São Sebastião se festeja em janeiro, gosta de andar sob a chuva, dizem os foliões que comem aguaceiro pelos descampados" (JURANDIR, 1992, p.171).

Nas fazendas, os foliões cantam, rezam as ladainhas em volta da imagem do santo e abrem espaço para o momento de "beijação" da imagem do santo padroeiro, onde, em filas, os devotos curvam-se e ajoelham-se diante do santo, pedindo-lhe a benção e proteção.

A chegada do santo às localidades adjacentes ou a outros municípios da ilha é sempre muito esperada e disputada e, em alguns lugares, há festas dançantes, corridas de cavalo, distribuição de comidas, etc. A visita do santo é oportunidade única para aqueles devotos que não podem participar dos festejos na sede de Cachoeira do Arari. Seu Edmundo, folião do santo, em depoimento, falou das senhoras idosas e dos demais moradores que não dispõem de condições financeiras para irem à Cachoeira e quão imensa é a alegria com que recebem a imagem em suas casas.

Tem muita gente que num tem as condição de vim pros festejo, pra igreja, pro mastro, pra essas coisa toda. Entô, já indo nas casa, a gente é muito bem arrecebido. A gente canta a chegada, tem a Ave Maria, a ladainha. É um prazê vê a alegria daquelas pessuas de idade, humirde, que já não pode vi. Eles faze o agradecimento, a oferta, de acordo com a condição, né!? Mata uma galinha, mata um pato, um porquinho, aí a gente se sente bem, porque sabe que aquelas pessuas num têm condição. Quando é aquelas que têm mais condição, dão uma oferta pro santo, dão uma ordi, né?! (Seu Edmundo, Folião de São Sebastião, 2007).

Hoje a peregrinação da imagem do santo inclui a capital paraense, Belém, no seu roteiro, por conta da grande quantidade de marajoaras que são devotos do santo e que residem na capital. Assim, enquanto uma Comissão percorre as cidades e fazendas pelo Marajó, outra Comissão peregrina em Belém, nas casas dos "filhos de Cachoeira", como assim se autodenominam esses marajoaras devotos.

Enquanto ocorre a peregrinação da imagem do santo, no dia 15 de novembro, um grupo de homens sai para cortar o mastro do santo, ou melhor, os mastros, o dos homens, o das mulheres e o das crianças, que se constituem em principais símbolos da festa, ao lado da imagem do santo. Os mastros dos homens e o das mulheres medem cerca de 10 metros de altura, já o das crianças, é menor e todos são de madeira de quaruba.

Os mastros são retirados das matas de uma fazenda próxima ao município, Fazenda Maragogipe, e tanto a derrubada como seu transporte é marcado por grande festa. Os homens que vão ao mato retirá-lo fazem do corte e derrubada, objeto de brincadeira e divertimento, pois eles levam para o local bebidas, comidas, banda de música, foguetes, fornecidos pelos padrinhos do mastro, e com muita animação derrubam e transportam os mastros.

A gente tira o mastro de dentro da mata, faz uma picada, a gente vai, derruba, tira a galharia dele todinho, e o pessoal vem trazendo "na marra" ele lá de dentro do mato. Quando se tira o mastro o pessoal que tá de 
camisa, rasga suas camisas, amarram no mastro, fazendo promessas ou agradecendo. (José Pio, responsável pela derrubada dos mastros de São Sebastião, 2007)

Sobre a introdução do mastro na festividade, de acordo com informativo da igreja Católica local, em 1940, em Cachoeira, um senhor chamado Raimundo Martins solicitou uma graça ao santo e alcançando a cura de uma enfermidade convocou familiares e amigos devotos do santo para erguerem um mastro em homenagem ao santo. A partir daí a tradição do mastro se manteve. Em 1946, devido também a uma graça alcançada por uma senhora por nome Celeste Santos, o mastro das mulheres passou a integrar a festa, surgindo em seguida, o mastro das crianças.

\section{O encontro da imagem do santo com os mastros: o religioso e lúdico}

$\mathrm{Na}$ tarde do dia 10 de janeiro, com acompanhamento da banda de música que toca ritmos carnavalescos, frevo e músicas regionais, começa a procissão dos mastros. A multidão inicia a caminhada a partir da casa dos juízes dos mastros e, quando os três mastros se encontram, percorrem as principais ruas da cidade em dança e muito barulho, seguindo para o lugar chamado Porteira, entrada da cidade, pelo campo. Na Porteira os mastros são deixados ao chão e a multidão espera pela chegada da imagem.

Muitos se dirigem ao local de saída da imagem do santo, a localidade Cuieiras, nos campos da Ilha, para acompanharem a imagem peregrina e quando possível, carregá-la, pois, durante todo o percurso a imagem do santo vai passando de mão em mão, sob a organização da freira que ora carrega, ora caminha sempre ao seu lado. As pessoas que acompanham a imagem do santo a fazem com certa informalidade. Enquanto os foliões, tocam, cantam e rezam a multidão que cerca a imagem ora canta, ora cala, ora conversa, ora reza, ora brinca, ora caminha mais ligeiro pela estrada de piçarra, ora para. De vez em quando, alguém solta um foguete e, assim, o percurso que inicia às $14 \mathrm{~h}$, chega à cidade por volta das $16 \mathrm{~h}$.

Quando o santo chega perto da cidade, na Porteira, ocorre o clímax da festa, pois é quando o povo que conduz o mastro encontra com aqueles que conduzem a imagem do santo. Os mastros são carregados acima das cabeças e perfilados para a imagem do santo passar. É um momento de muita emoção para os devotos que em uníssono gritam: Viva São Sebastião!

A imagem segue em frente, em direção à igreja da Matriz, enquanto, para trás, ficam os mastros que voltam à festa sob o som da banda de música, dando a impressão de estar acontecendo um animado carnaval de rua, com pessoas enfeitadas com folhas, homens travestidos de mulheres, bebidas típicas, brincadeiras, danças, lutas, guerra de maisena e lama, numa mistura de fé e carnaval que marca uma das mais divertidas homenagens a São Sebastião no estado do Pará.

Fazendo referência à festa e a informalidade que nela se observa, Maués (2011) destaca que a folgança, a brincadeira, a irreverência é parte do catolicismo popular, bem como, as rezas, missas e procissões. Em seu estudo sobre festas de santo na região do litoral paraense, Maués (2011) faz destaque a esta manifestação, como próprio do catolicismo popular. 


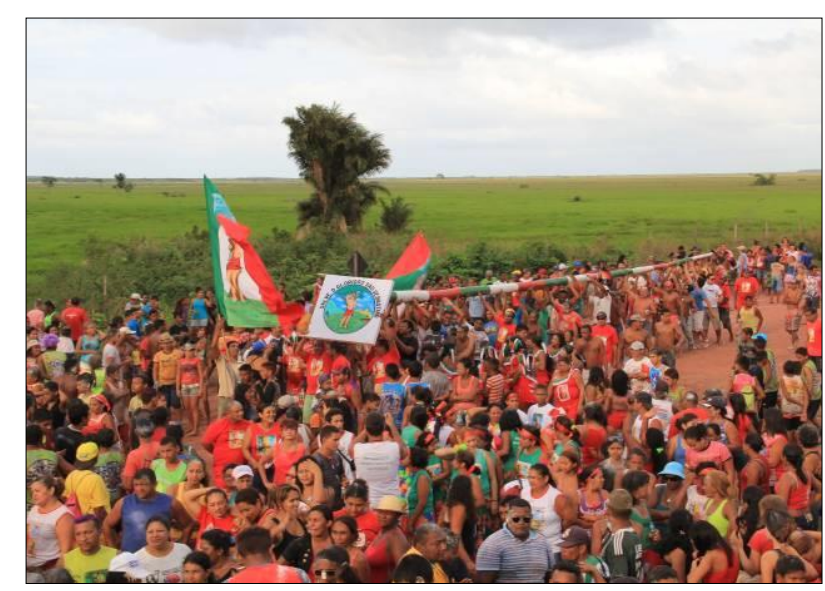

Figura 1 - Mastros erguidos, seguindo a imagem do santo na Porteira $d a$ cidade Fonte: Boulhosa (2007)

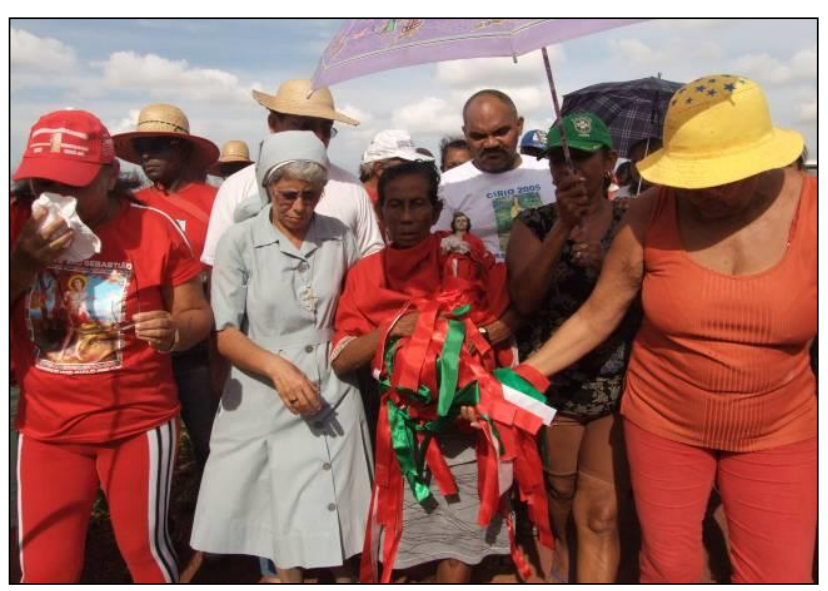

Figura 2 - Ultima peregrinação da imagem do santo ruma à sede da cidade Fonte: Boulhosa (2007)

O catolicismo não tem peias, restrições, privações. Isso permite o comportamento folgazão das pessoas que festejam Santo Antônio, carregando seu mastro e bebendo cachaça, soltando impropérios e dando vivas ao santo, ao mesmo tempo em que realizam uma espécie de dança que simula, nos movimentos executados com o mastro ("pau" do santo), um ato sexual. Isso permite também que, na festa religiosa maior dos vigienses, o Círio de Nossa Senhora de Nazaré, os pescadores que se salvaram de naufrágios paguem suas promessas acompanhando a procissão molhados, com vestes sumárias, carregando as boias com que se mantiveram até serem recolhidos por embarcações - numa alusão simbólica muito clara ao "milagre" —, mas, ao mesmo tempo, divertindo-se alegremente, e bebendo a ponto de terminarem o cortejo embriagados (MAUÉS, 2011, p. 7).

Em seguida, o santo segue para a igreja e os mastros são levados para as margens do rio Arari, para serem adornados e, finalmente, fincados ao chão, onde permanecerão até o dia 20 de janeiro, dia de São Sebastião, quando serão derrubados.

O evento todo é regado a muita música e bebida. A bebida que é distribuída durante a festa possui um preparo especial para o evento e figura como sendo típica da festividade: cachaça ou álcool misturado com leite de búfalo, açúcar e anilina e está pronto o "Leite de onça", que é servido aos carregadores dos mastros e vendido no arraial. Aos carregadores do mastro não é aceita a hipótese de faltar o "Leite de onça", pois isso "ajuda na caminhada", justificam.

Em volta dos mastros ocorre outra manifestação da festa, a luta marajoara, que se caracteriza como disputa de força física entre duas pessoas que, em posição agachada, trabalham com as pernas e braços para derrubar o adversário ao chão ou fazer-lhe pedir clemência, apenas com o uso da força do corpo. Na luta, apenas dois adversários entram em disputa, não sendo 
BOULHOSA, Marinete Silva . Festividade de São Sebastião, de Cachoeira do Arari (...). Revista Hospitalidade. São Paulo,

ISSN 1807-975X volume 14, n.01, p.01-15, agosto de 2017.

permitida intromissão de mais ninguém, embora, algumas vezes, termine em briga generalizada. A luta se dá durante quase todo o percurso do mastro, entre homens, mulheres e até crianças.

No transcorrer da festividade acontece o arraial, montado próximo a igreja matriz, que se constitui ponto de encontro e socialização. Todas as noites ocorrem às novenas a São Sebastião, além de bingos, leilões de donativos, apresentação de grupos folclóricos e de bandas de músicas, provas de corridas do cavalo marajoara, campeonato de luta marajoara e festas dançantes com aparelhagem, em vários locais da cidade.

O encerramento da festividade acontece no dia 20 de janeiro e se dá com a realização de procissão e missa dos vaqueiros pela manhã, percorrendo as principais ruas da cidade. A missa ocorre na frente da igreja e os vaqueiros a assistem montados em seus cavalos, revelando com isso a força da tradição do povo devoto do santo.

À tarde, por volta das $16 \mathrm{~h}$, reinicia-se a festa popular com a disputa das bandeiras do santo, que serão retiradas do alto dos mastros. Posteriormente, acontece a tradicional derrubada dos mastros, quando os três são cortados com machados desamolados, de modo que os inúmeros devotos tenham a oportunidade de darem machadadas sem o risco dos mastros tombarem logo. Depois de derrubados, a multidão se reúne para levar os mastros até as casas dos juízes dos mastros do próximo ano. As ruas da cidade ficam novamente tomadas pela multidão que acompanha o mastro, multidão esta, bem maior que a do dia 10 de janeiro. Essa procissão dura horas, finalizando, muitas vezes, as sete ou oito horas da noite, com a entrega dos mastros. A festividade tem seu encerramento oficial, com a missa às $20 \mathrm{~h}$ e com a queima de fogos de artifícios a meia noite.

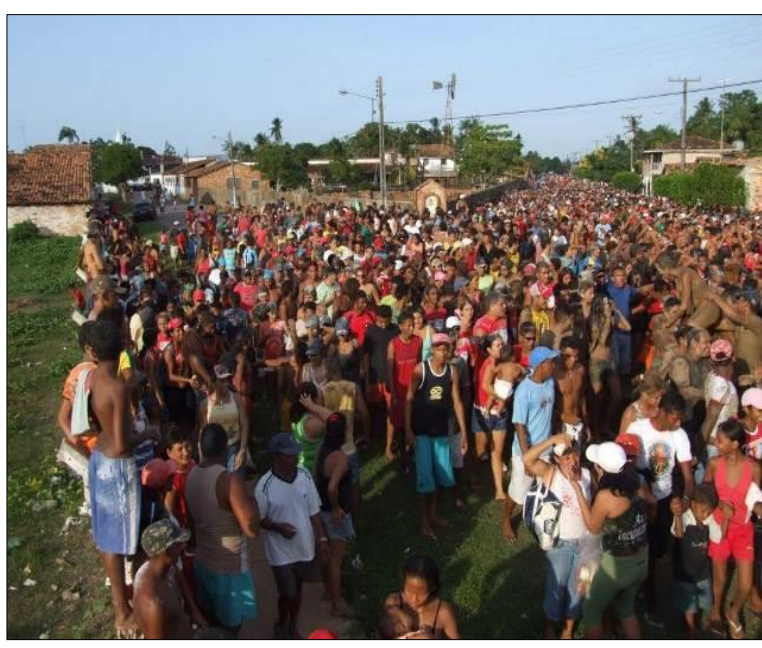

Figura 3 - Multidão na procissão dos mastros pelas ruas de Cachoeira do Arari. Fonte: Boulhosa (2007)

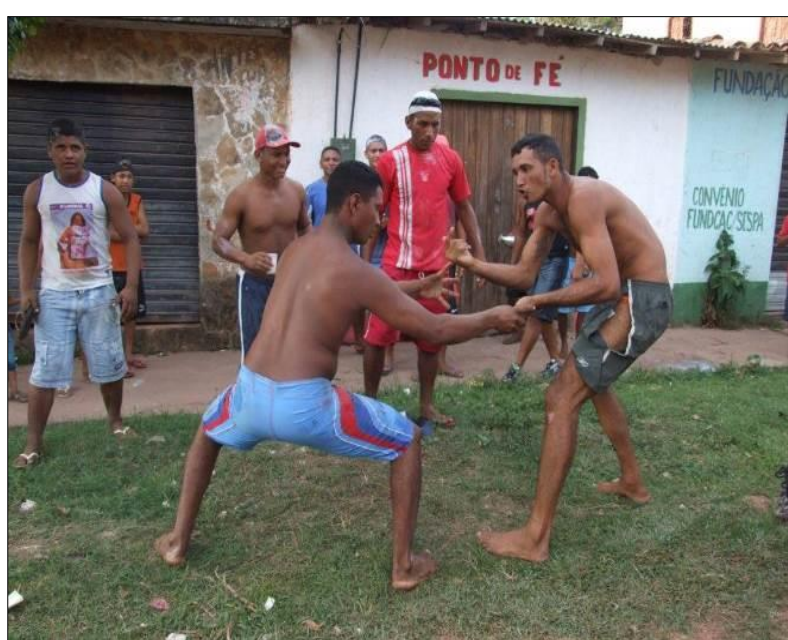

Figura 4 - Luta marajoara: brincadeira no transcorrer da procissão dos mastros. Fonte: Boulhosa (2007) 


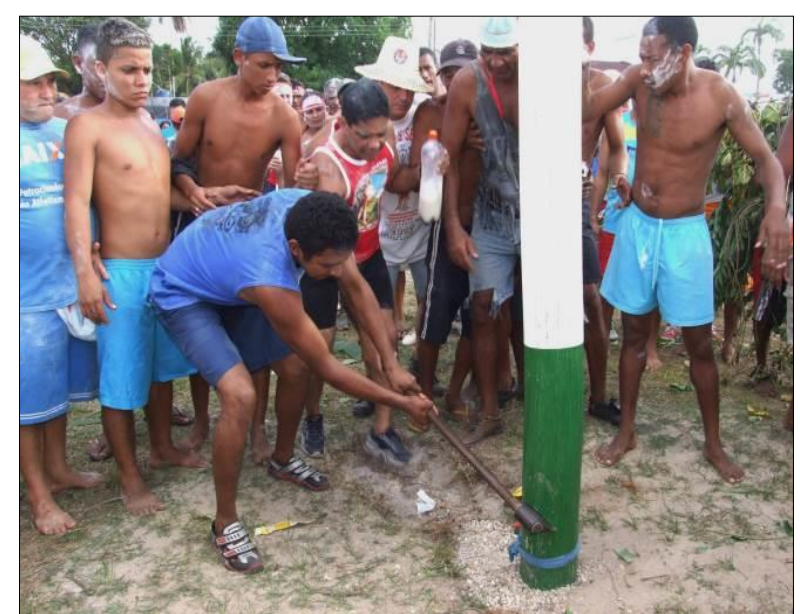

Figura 5- Derrubada do mastro com machado. Cachoeira do Arari. Fonte: Boulhosa, 2007.

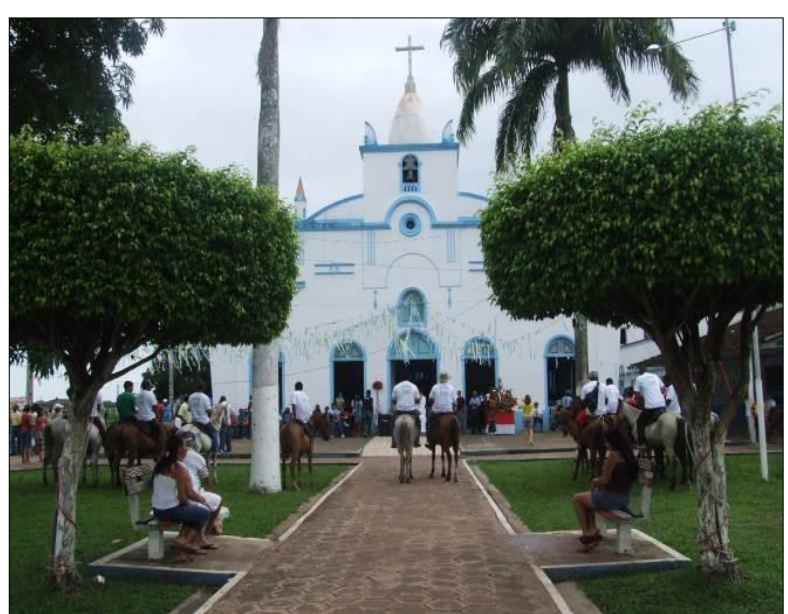

Figura 6 - Missa dos Vaqueiros. Cachoeira do Arari. Fonte: Boulhosa, 2007

Corrêa (2013) explica que a festa é um acontecimento coletivo que ultrapassa o sentido da comemoração e atua na formação dos vínculos que fundamentam a experiência humana coletiva. Ela marca histórias, pontuando e regulando o curso da vida das pessoas.

O que se observa, na verdade, é que as características de informalidade, de inversão, de brincadeira, de resistência à ordem, de mistura de elementos, muitas vezes conflitantes, é uma forma de sincretismo que extrapola o religioso, mas não deixa de ser parte da religião. É um ritual que apresenta um conjunto de mensagens que dizem respeito à própria vida social experimentada cotidianamente pelos grupos e categorias sociais (ALVES, 1980). É a manifestação da identidade

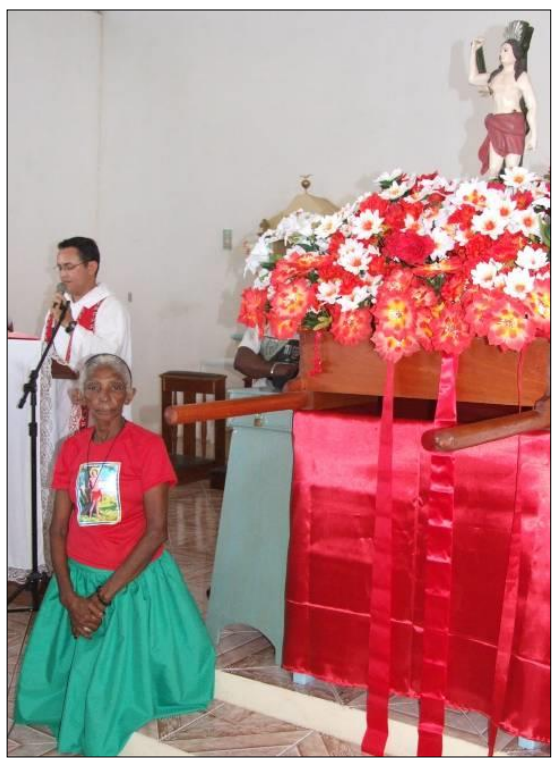

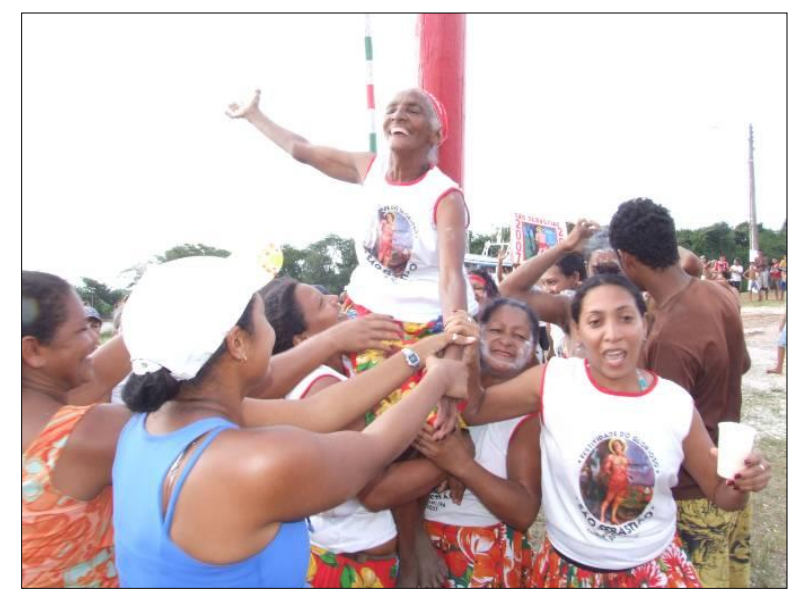

Figuras 8 e 9 - A mesma devota, em momentos diferentes, porém, inseparáveis nas comemorações a São Sebastião. Cachoeira do Arari. Fonte: Boulhosa, 2007 
amazônica, que tem na festa dos santos, um de seus principais elementos, como apontou Raymundo Maués (1999).

\section{Considerações finais}

Pelo exposto neste artigo sobre a religiosidade da população amazônica, com destaque às festas de santo e pela caracterização da Festividade de São Sebastião de Cachoeira do Arari, constata-se que essa manifestação da cultura e da identidade amazônica pode contribuir para o desenvolvimento do turismo cultural na região, induzindo com isso o resgate, a valorização, a promoção da cultura amazônica e, consequentemente, o homem amazônico.

O universo marajoara possui um amplo e complexo sistema cultural, em que o ser e o fazer de sua gente é manifestado na simplicidade do cotidiano ou no extraordinário de eventos ritualizados, quando as sociedades saem de sua rotina para viverem a festa, a fé, a vida.

A religiosidade do homem amazônico, aqui em destaque as festas de santos católicos, constitui-se em atrativo turístico e cultural na região, pois, além de eventos que suscitam a fé e a devoção, elas são acontecimentos que caracterizam a própria identidade amazônica, logo comunicam o ser amazônico com suas práticas culturais resultantes de séculos de história, crenças, modo de vida, valores, tradições, rituais, enfim, práticas culturais que, ao mesmo tempo em que particularizam essa gente, a universalizam no contexto brasileiro e internacional. É o ser amazônida que se expressa, que se revela, que se impõe, ora com fé, com força, ora com leveza e brincadeira.

Assim, pensar o desenvolvimento do turismo na região por intermédio da promoção do turismo cultural, demanda, antes de tudo, pensar nessa gente, na valorização não só da manifestação cultural, mas do homem produtor da cultura. Promover o turismo cultural no Marajó, sob bases sustentáveis, implica, necessariamente, na valorização das práticas culturais, no respeito às diferenças religiosas e na valorização da sociedade marajoara, para se evitar o risco de promover apenas o espetáculo e não o desenvolvimento do homem marajoara.

Esse turismo só será sustentável se for capaz de transformar-se em atividade importante para o desenvolvimento socioeconômico da população, a partir da sua inserção no processo produtivo, com geração de renda e emprego e com a elevação de sua qualidade de vida, pois, como mostrado neste trabalho, a região do Marajó, ainda se configura como uma região de exclusão social no Brasil.

\section{Referências}

ALVES, I. O carnaval devoto: um estudo sobre a festa de Nazaré e Belém. Petrópolis: Vozes, 1980. (Coleção de Antropologia, n. 13).

ANGELO, E. R. B. O segmento do turismo cultural na cidade de Petrópolis: patrimônio, cultura e cidadania. In: SIMPÓSIO NACIONAL DE HISTÓRIA - ANPUH, 26., 2011, São Paulo. Anais... São Paulo: ANPUB, 2011.

BOULHOSA, M. S. Entre a sela e o santo: um estudo sobre a identidade do vaqueiro marajoara. 2007. Dissertação (Mestrado) - Programa de Pós-Graduação em Ciências Sociais, Universidade Federal do Pará. Belém, 2007. 
BOULHOSA, M. S. Ecoturismo no Marajó: o desafio do desenvolvimento sustentável, num cenário de contradições. 2001. Monografia (Especialização em Planejamento do Desenvolvimento) - Núcleo de Altos Estudos Amazônicos (NAEA/UFPA), Belém, 2001.

CORRÊA, J. A. G. A arte de festejar da alternância da festa e de suas expressões materiais. Textos escolhidos de cultura e artes populares, Rio de Janeiro, v.10, n.1, p. 183-199, maio 2013.

GALVÃO, E. Vida religiosa do caboclo da Amazônia. Boletim do Museu Nacional. Antropologia, Rio de Janeiro, n. 15, 1953.

INSTITUTO BRASILEIRO DE GEOGRAFIA E ESTATÍSTICA - IBGE. Censo demográfico brasileiro. Rio de Janeiro: IBGE, 2010.

JURANDIR, D. Marajó. 3. ed. Belém: Cejup, 1992.

LAPLANTINE, F. Aprender antropologia. São Paulo: Brasiliense, 2003.

MAUÉS, R. H. Outra Amazônia: os santos e o catolicismo popular. Norte Ciência, v. 2, n. 1, p. $1-26,2011$.

MAUÉS, R. H. Padres, pajés, santos e festas. Catolicismo popular e controle eclesiástico. Belém: Cejup, 1995.

MAUÉS, R. H. Uma outra “invenção” da Amazônia: religiões, histórias, identidades. Belém: Cejup, 1999.

MOLETTA, V. F. Turismo cultural. 3. ed. Porto Alegre: SEBRAE, 2001.

PARÁ. Plano de Desenvolvimento Turístico - PDT Pará. Belém, 2001.

PARÁ. Relatório Executivo do Plano Estratégico de Turismo do Estado do Pará (2012 2020). Belém, $\mathrm{s} / \mathrm{d}$. Disponível em: http://www.paraturismo.pa.gov.br/sites/default/files/Relatorio_Executivo.pdf> . Acesso em: 2 abr. 2016.

PIRES, M. J. Lazer e turismo cultural. Barueri: Manole, 2001.

Recebido em: 19/04/2016

Revisto em: 16/06/2016

Aprovado em: 06/07/2017 